\title{
Comparison of Prognostic Scores for Upper Gastrointestinal Bleeding in the Hepato-Gastro-Enterology Department of Campus Teaching Hospital of Lome
}

\author{
Aklesso Bagny1,2, Lidawu Roland-Moïse Kogoe1, Late Mawuli Lawson-Ananissoh1,2, \\ Laconi Yeba Kaaga1, Debehoma Redah', Mawunyo Henoc Gbolou1, \\ Yendoukoa Yves Kanake ${ }^{1}$
}

${ }^{1}$ Departement of Gastroenterology, Teaching Hospital Campus of Lome, Lome, Togo

${ }^{2}$ Departement of Gastroenterology, University of Lome, Lome, Togo

Email: ybagny@yahoo.fr

How to cite this paper: Bagny, A., Kogoe, L.R.-M., Lawson-Ananissoh, L.M., Kaaga, L.Y., Redah, D., Gbolou, M.H. and Kanake, Y.Y. (2021) Comparison of Prognostic Scores for Upper Gastrointestinal Bleeding in the Hepato-Gastro-Enterology Department of Campus Teaching Hospital of Lome. Open Journal of Gastroenterology, 11, 161-171. https://doi.org/10.4236/ojgas.2021.119017

Received: August 17, 2021

Accepted: September 7, 2021

Published: September 10, 2021

Copyright $\odot 2021$ by author(s) and Scientific Research Publishing Inc. This work is licensed under the Creative Commons Attribution International License (CC BY 4.0).

http://creativecommons.org/licenses/by/4.0/ (c) (i) Open Access

\begin{abstract}
Objective: To evaluate and compare the prognostic contribution of different UGIB prognostic scores. Patients and Method: Descriptive cross-sectional study with retrospective collection conducted from January 2014 to December 2019. Patients hospitalized in the Gastroenterology Department of Campus Teaching Hospital of Lome for upper gastrointestinal hemorrhage were included. The analytical component of this study had consisted of an evaluation of the sensitivity and specificity of different prognostic scores (GBS, mGBS, FRS, CRS, AIMS65) in predicting the occurrence of death and/or re-bleeding within 42 days. These different scores were compared using ROC (Receiver Operating Characteristic) curves. Results: We included 314 patients in our study. The male to female sex ratio was 2.48. Fibroscopy found non-related portal hypertension UGIB in $70.94 \%$ of the cases. The "FRS" was the most accurate score in predicting death or re-bleeding in all patients. The "FRS" was the most precise score in predicting the occurrence of spotting in all patients. The "FRS" was the most accurate score in predicting death among all patients. The mortality of patients at low risk of death (below the threshold value) was $2.2 \%$ for the "FRS", 9.3\% for the "CRS", $0 \%$ for the "GBS" ( $p=0.565$ ), $50 \%$ for the "mGBS" and $11.4 \%$ for the "AIMS65". Scores were more accurate for non-related portal hypertension UGIB. Conclusion: The "FRS" and the "CRS" are two precise scores in predicting the occurrence of an incident in the event of upper gastrointestinal hemorrhage. However, these scores were less effective in related portal hypertension UGIB.
\end{abstract}




\section{Keywords}

Upper Gastrointestinal Bleeding, Prognostic Scores, Rockall, Glasgow-Blatchford, AIMS65, Lome

\section{Introduction}

Upper gastrointestinal bleeding (UGIB) is a frequently encountered medical emergency in clinical practice [1]. The estimated in-hospital prevalence in emergency departments is $5 \%$ in developed countries [2]. The etiologies of UGIB are classified into two categories, depending on the mechanism of occurrence: related portal hypertension upper GI bleeding and non-related portal hypertension UGIB [3]. Related portal hypertension UGIB is a major complication of cirrhosis [4]. Mortality from UGIB is high, ranging from $6 \%$ to $10 \%$ for non-related portal hypertension UGIB, and $17 \%$ to $24 \%$ for related portal hypertension UGIB [5] [6]. Various scores taking into account clinical and/or endoscopic parameters have been described in recent years [7] [8], with the aim of facilitating emergency management of patients [9] [10]. The interest of these scores is the identification of high-risk patients, i.e. those requiring hospital management. Different prognostic scores such as the Glasgow-Blatchford bleeding score (GBS), the modified Glasgow-Blatchford bleeding score (mGBS), the Full Rockall Score (FRS), the Clinical Rockall Score (CRS) and the AIMS65 are used to predict a high risk of rebleeding and/or mortality in patients [7] [11]. In Togo, Bagny et al. [12] reported in 2012 a hospital incidence of 7.32\% in the Gastroenterology Department of Campus Teaching Hospital of Lome, with a mortality rate of 5\%. However, this study only aimed at evaluating the etiological profile of UGIB at the Campus Teaching Hospital of Lome. Moreover, patients seen in consultation for upper GI bleeding are systematically hospitalised, due to the absence of a proven prognostic score to identify low-risk patients. Therefore, we felt it was necessary to conduct this study with the objective of evaluating and comparing the accuracy of different prognostic scores for UGIB.

\section{Patients and Method}

This is a cross-sectional descriptive study with retrospective collection conducted from January 2014 to December 2019. Patients hospitalized in the Gastroenterology Department of Campus teaching hospital of Lome for upper GI bleeding or who presented an upper GI bleeding during hospitalization and who performed the fibroscopy and were followed for 42 days were included. Patients who were lost to follow-up or did not perform the fibroscopy were excluded. The anonymity of the patients had been respected. Upper GI bleeding was defined as the occurrence of haematemesis or melena. The patients had initially received a medical resuscitation protocol before the fibroscopy was performed. Only hemodynamically stable patients were admitted for fibroscopy. The data were processed using Stata 13 software. 
Our study included a descriptive part of the study population and an analytical part. The analytical part consisted of an evaluation of the sensitivity and specificity of different prognostic scores (GBS, mGBS, FRS, CRS, AIMS65) in predicting the occurrence of death and rebleeding. These different scores were compared using ROC curves (Receiver Operating Characteristic). The cut-off values were 0 for CRS, 2 for FRS, 1 for GBS, 1 for mGBS and 0 for AIMS65, in accordance with those used in the literature [13] [14]. Above these threshold values, patients were considered to be at high risk of complications (rebleeding or death). The results were presented as mean, standard deviation and ranges for quantitative variables; numbers and percentages for qualitative variables. Statistical tests used were Fischer's exact test and Chi-squared test for qualitative variables; and Student's t-test for quantitative variables. The difference between the variables tested was significant for $\mathrm{p} \leq 0.05$.

\section{Results}

We included 314 patients in our study. The sex ratio M/F was 2.48. Fibroscopy found non-related portal hypertension UGIB in $70.94 \%$ of cases. Male patients represented $76.12 \%$ of related portal hypertension UGIB and $69.88 \%$ of non-related portal hypertension UGIB $(\mathrm{p}=0.34)$. The mean age of patients hospitalised for related portal hypertension UGIB was $43.02 \pm 14.05$ years, compared to $46.06 \pm 17.64$ years $(\mathrm{p}=0.21)$. Non-related portal hypertension UGIB was statistically associated with use of non-steroidal anti-inflammatory drugs ( $\mathrm{p}$ $=0.001)$, the presence of hypertension $(\mathrm{p}=0.003)$ and abdominal pain $(\mathrm{p}=$ 0.021 ). Related portal hypertension UGIB was statistically associated with rebleeding $(\mathrm{p}=0.001)$ and death $(\mathrm{p}=0.001)$. The mean haemoglobin level of patients hospitalised with non-related portal hypertension UGIB (08.99 \pm 3.49 $\mathrm{g} / \mathrm{dl}$ ) was higher than that of patients hospitalised with related portal hypertension UGIB $(07.24 \pm 3.49 \mathrm{~g} / \mathrm{dl})$ with a significant difference $(\mathrm{p}<0.001)$. Thrombocytopenia $(\mathrm{p}<0.001)$, anaemia $(\mathrm{p}<0.001)$ and decreased prothrombin level $(\mathrm{p}<0.001)$ were statistically associated with related portal hypertension UGIB.

The different prognostic scores had a higher mean value in related portal hypertension UGIB (Table 1). The difference in mean score values between related portal hypertension and non-related portal hypertension etiology was significant $(\mathrm{p}<0.05)$, as shown in Table 1 . The clinico-biological characteristics of the patients according to the etiologies are reported in Table 1.

Comparison of the performance of the different scores in predicting the occurrence of an event (death or rebleeding).

Analysis of the ROC curve for each of the five scores (prediction of death or rebleeding in the entire study population) showed an area of 0.664 for the FRS, 0.605 for the CRS, 0.529 for the GBS, 0.504 for the mGBS and 0.613 for the AIMS65 (Figure 1; Table 2). This difference was only significant between FRS and CRS ( $p<0.001)$; FRS and GBS $(\mathrm{p}=0.003)$; FRS and mGBS $(\mathrm{p}<0.001)$; AIMS65 and mGBS $(\mathrm{p}=0.014)$. The FRS was therefore the most accurate score 
in predicting the occurrence of death and/or rebleeding in all our patients. No score was effective in predicting the occurrence of an event (rebleed or death) in patients with related portal hypertension UGIB $(\mathrm{p}=0.523)$; the same was true for patients with non-related portal hypertension UGIB $(\mathrm{p}=0.911)$ (Figure 1).

Table 1. Clinical and biological features.

\begin{tabular}{|c|c|c|c|}
\hline & $\begin{array}{l}\text { Portal hypertension } \\
\text { related UGIB }\end{array}$ & $\begin{array}{l}\text { Non related portal } \\
\text { hypertension UGIB }\end{array}$ & $\mathrm{p}$ \\
\hline Age (years) & $43.02 \pm 14.05$ & $46.06 \pm 17.64$ & 0.210 \\
\hline Sex (male) & $76.12 \%$ & $69.88 \%$ & 0.339 \\
\hline Hepatic insufficiency & $90.47 \%$ & $9.53 \%$ & $<0.001$ \\
\hline Chronic liver disease & $92.85 \%$ & $7.15 \%$ & $<0.001$ \\
\hline Ethylism & $32.91 \%$ & $67.09 \%$ & 0.330 \\
\hline Non-steroidal anti-inflammatory & $14.86 \%$ & $85.14 \%$ & 0.001 \\
\hline Abdominal pain & $22.40 \%$ & $77.60 \%$ & 0.021 \\
\hline Automedication & $21.29 \%$ & $78.71 \%$ & 0.022 \\
\hline Arterial hypertension & $08.57 \%$ & $91.43 \%$ & 0.003 \\
\hline Syncope & $25 \%$ & $75 \%$ & 0.677 \\
\hline Altered consciousness & $28.38 \%$ & $71.62 \%$ & 0.123 \\
\hline Hepatic insufficiency signs & $88.88 \%$ & $11.12 \%$ & $<0.001$ \\
\hline Portal hypertension signs & $88 \%$ & $12 \%$ & $<0.001$ \\
\hline Hemoglobin rate $(\mathrm{g} / \mathrm{dl})$ & $07.24 \pm 2.31$ & $08.99 \pm 3.49$ & $<0.001$ \\
\hline White blood cells $(/ \mathrm{ml})$ & $8648 \pm 6847$ & $8237 \pm 5102$ & 0.627 \\
\hline Platelets (/ml) & $141,612 \pm 16,110$ & $198,945 \pm 8847$ & $<0.001$ \\
\hline Urea $(g / 1)$ & $0.50 \pm 0.52$ & $0.53 \pm 0.47$ & 0.708 \\
\hline Creatininemia (mg/l) & $12.74 \pm 9.67$ & $19.31 \pm 29.63$ & 0.100 \\
\hline Prothrombin rate & $54.90 \pm 15.35$ & $71.11 \pm 19$ & $<0.001$ \\
\hline Albumin (g/l) & $31.15 \pm 7.54$ & $28.83 \pm 11.97$ & 0.081 \\
\hline ASAT (UI/l) & $229 \pm 911$ & $111 \pm 333$ & 0.218 \\
\hline ALAT (UI/l) & $86.57 \pm 146.02$ & $82.93 \pm 242.24$ & 0.919 \\
\hline Rebleeding & $54.83 \%$ & $45.16 \%$ & 0.001 \\
\hline Death & $71.42 \%$ & $28.58 \%$ & $<0.001$ \\
\hline FRS & $4.85 \pm 1.34$ & $3.53 \pm 1.34$ & $<0.001$ \\
\hline CRS & $1.95 \pm 1.59$ & $1.09 \pm 0.93$ & $<0.001$ \\
\hline GBS & $10.58 \pm 3.26$ & $8.86 \pm 3.40$ & $<0.001$ \\
\hline mGBS & $9.08 \pm 2.73$ & $8.04 \pm 3.17$ & 0.018 \\
\hline AIMS65 & $0.67 \pm 0.80$ & $0.42 \pm 0.58$ & 0.008 \\
\hline
\end{tabular}

UGIB: Upper Gastro Intestinal Bleeding; ALAT: Alanine amino transférase; ASAT: Aspartate amino transférase; FRS: Full Rockall Score; CRS: Clinical Rockall Score; GBS: Glasgow-Blatchford Bleeding Score; mGBS: modified Glasgow-Blatchford Bleeding Score; AIMS65: Albumin, international normalized ratio, mental status, systolic blood pressure, age. 
Table 2. Area under ROC curves.

\begin{tabular}{|c|c|c|c|c|}
\hline & & $\begin{array}{l}\text { Patients } \\
(\mathrm{N}=234)\end{array}$ & $\begin{array}{l}\text { Portal hpertension } \\
\text { related UGIB } \\
(\mathrm{N}=68)\end{array}$ & $\begin{array}{l}\text { Non-related portal } \\
\text { hypertension UGIB } \\
(\mathrm{N}=166)\end{array}$ \\
\hline & & \multicolumn{3}{|c|}{ AUROC $(95 \%$ CI $)$} \\
\hline \multirow{3}{*}{ FRS } & Incident & $0.664(0.597-0.731)$ & $0.508(0.358-0.658)$ & $0.517(0.356-0.678)$ \\
\hline & Saignement & $0.639(0.564-0.715)$ & $0.467(0.310-0.624)$ & $0.517(0.356-0.678)$ \\
\hline & Décès & $0.717(0.647-0.786)$ & $0.643(0.481-0.840)$ & $0.609(0.189-1.000)$ \\
\hline \multirow{3}{*}{ CRS } & Incident & $0.605(0.532-0.678)$ & $0.490(0.336-0.644)$ & $0.480(0.329-0.638)$ \\
\hline & Saignement & $0.588(0.507-0.669)$ & $0.447(0.285-0.609)$ & $0.484(0.329-0.638)$ \\
\hline & Décès & $0.663(0.584-0.742)$ & $0.636(0.470-0.801)$ & $0.642(0.249-1.000)$ \\
\hline \multirow{3}{*}{ GBS } & Incident & $0.529(0.456-0.603)$ & $0.499(0.399-0.659)$ & $(0.523(0.369-0.677)$ \\
\hline & Saignement & $0.532(0.452-(0.612)$ & $0.500(0.330-0.669)$ & $0.523(0.369-0.677)$ \\
\hline & Décès & $0.564(0.483-0.644)$ & $0.542(0.343-0.741)$ & $0.792(0.607-0.977)$ \\
\hline \multirow{3}{*}{ mGBS } & Incident & $0.504(0.432-0.576)$ & $0.497(0.331-0.651)$ & $0.535(0.390-0.679)$ \\
\hline & Saignement & $0.509(0.433-0.584)$ & $0.535(0.390-0.679)$ & $0.522(0.352-0.692)$ \\
\hline & Décès & $0.534(0.453-0.615)$ & $0.525(0.325-0.726)$ & $0.839(0.680-0.990)$ \\
\hline \multirow{3}{*}{$\begin{array}{l}\text { AIMS } \\
65\end{array}$} & Incident & $0.613(0.544-0.682)$ & $0.550(0.406-0.693)$ & $0.493(0.351-0.634)$ \\
\hline & Saignement & $0.589(0.515-0.663)$ & $0.476(0.330-0.623)$ & $0.493(0.351-0.634)$ \\
\hline & Décès & $0.659(0.580-0.737)$ & $0.625(0.414-0.836)$ & $0.549(0.277-0.821)$ \\
\hline
\end{tabular}

UGIB: Upper gastrointestinal bleeding; CI: Confidence interval; AUROC: Area Under Receiver Operating Characteristic; FRS: Full Rockall Score; CRS: Clinical Rockall Score; GBS: Glasgow-Blatchford Bleeding Score; mGBS: Modified Glasgow-Blatchford Bleeding Score; AIMS65: Albumin, international normalized ratio, mental status, systolic blood pressure, age.

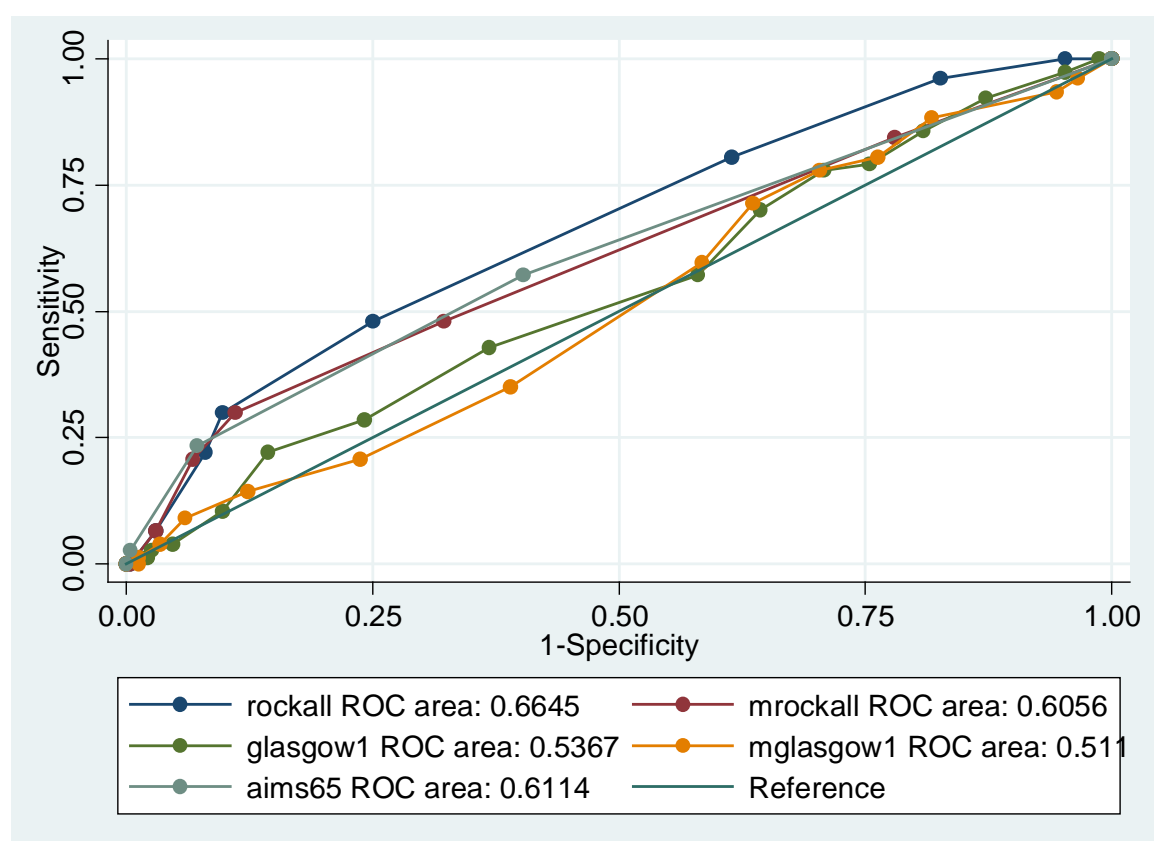

Figure 1. ROC curves in predicting the occurrence of an incident. ROC: Receiver Operating Characteristic. 


\subsection{Comparison of the Performance of Different Scores in Predicting the Occurrence of a Rebleed}

Analysis of the ROC curve for each of the five scores (prediction of rebleeding in the whole study population) showed an area of 0.639 for FRS, 0.588 for CRS, 0.532 for GBS, 0.509 for mGBS and 0.589 for AIMS65 (Figure 2; Table 2). This difference in performance was only significant between FRS and mGBS ( $p=$ $0.009)$; FRS and GBS ( $p=0.029)$; FRS and CRS $(p=0.001)$. The FRS was therefore the most accurate score in predicting the occurrence of a rebleed in all our patients. No score was effective in predicting the occurrence of a rebleed in patients with related portal hypertension UGIB ( $p=0.429)$; the same was true in patients with related portal hypertension UGIB $(\mathrm{p}=0.911)$ (Figure 2).

\subsection{Comparison of the Performance of Different Scores in Predicting the Occurrence of Death}

Analysis of the ROC curve for each of the five scores (prediction of death in the entire study population) showed an area of 0.717 for the FRS, 0.564 for the GBS, 0.663 for the CRS, 0.534 for the mGBS and 0.659 for the AIMS65 (Figure 3; Table 2). This difference in performance was only significant between FRS and mGBS ( $p=0.004)$; FRS and GBS ( $=0.001)$; CRS and GBS $(\mathrm{p}=0.039)$; CRS and mGBS $(p=0.014)$. The FRS was therefore the best predictor of death in all our patients.

Comparison of the area under the ROC curves of the FRS and AIMS65 showed a higher value in patients with related portal hypertension UGIB than in patients with non-related portal hypertension UGIB (FRS: 0.643 vs 0.609; AIMS65: 0.625 vs 0.549 ). The area under the ROC curves for CRS, GBS and mGBS was higher in non-related portal hypertension UGIB (CRS: 0.642 vs 0.636; GBS: 0.792 vs 0.535 ; mGBS: 0.839 vs 0.519 ). In non-related portal hypertension UGIB patients, there was a significantly higher accuracy of mGBS (AUROC: $0.839, \mathrm{p}<0.001$ ) compared to the other scores. There was no significant difference between the areas of the ROC curves of the different scores (prediction of the occurrence of death) in patients with related portal hypertension UGIB ( $\mathrm{p}=0.503)$ (Figure 3 ).

The mortality of patients at low risk of death (below the threshold value) was $2.2 \%$ for FRS, $9.3 \%$ for CRS, $0 \%$ for GBS ( $\mathrm{p}=0.565$ ), $50 \%$ for $\mathrm{mGBS}$ and $11.4 \%$ for AIMS65. This mortality was higher in patients with related portal hypertension UGIB $(\mathrm{p}<0.001)$. The GBS (sensitivity $=100 \%$; negative predictive value $=$ $100 \%$ ), the FRS (sensitivity $=98.21 \%$; negative predictive value $=97.72 \%$ below threshold) and the CRS (sensitivity $=89.28$; negative predictive value $=90.62 \%$ below threshold) were therefore the best performing scores in detecting patients at low risk of death (Table 3 ).

\section{Discussion}

The main limitation of our study was its retrospective nature. Some patients 
were not included because their records were not usable.

We compared the ROC curves, sensitivities and specificities of five different scores to assess their accuracy in assessing the probability of death and/or rebleeding. In line with the literature, these scores showed moderate effectiveness in predicting the different events studied, especially in non-related portal hypertension UGIB [15].

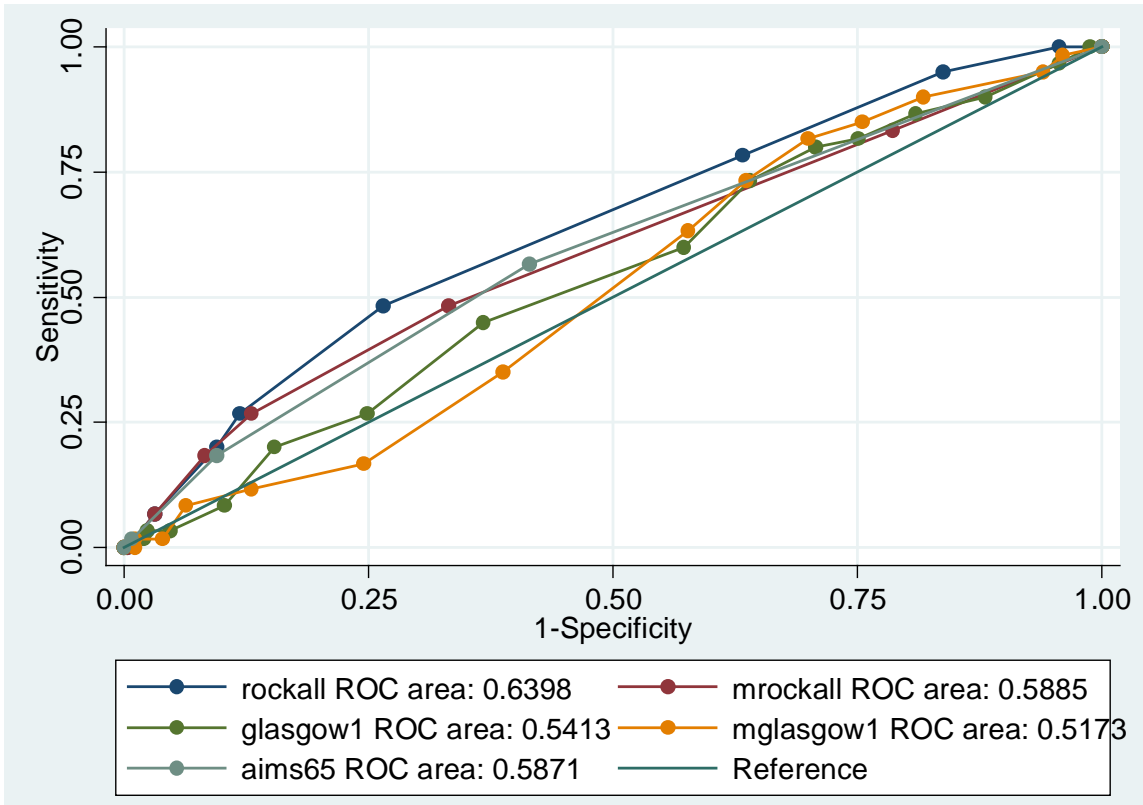

Figure 2. ROC curves in predicting the occurrence of rebleeding. ROC: Receiver Operating Characteristic.

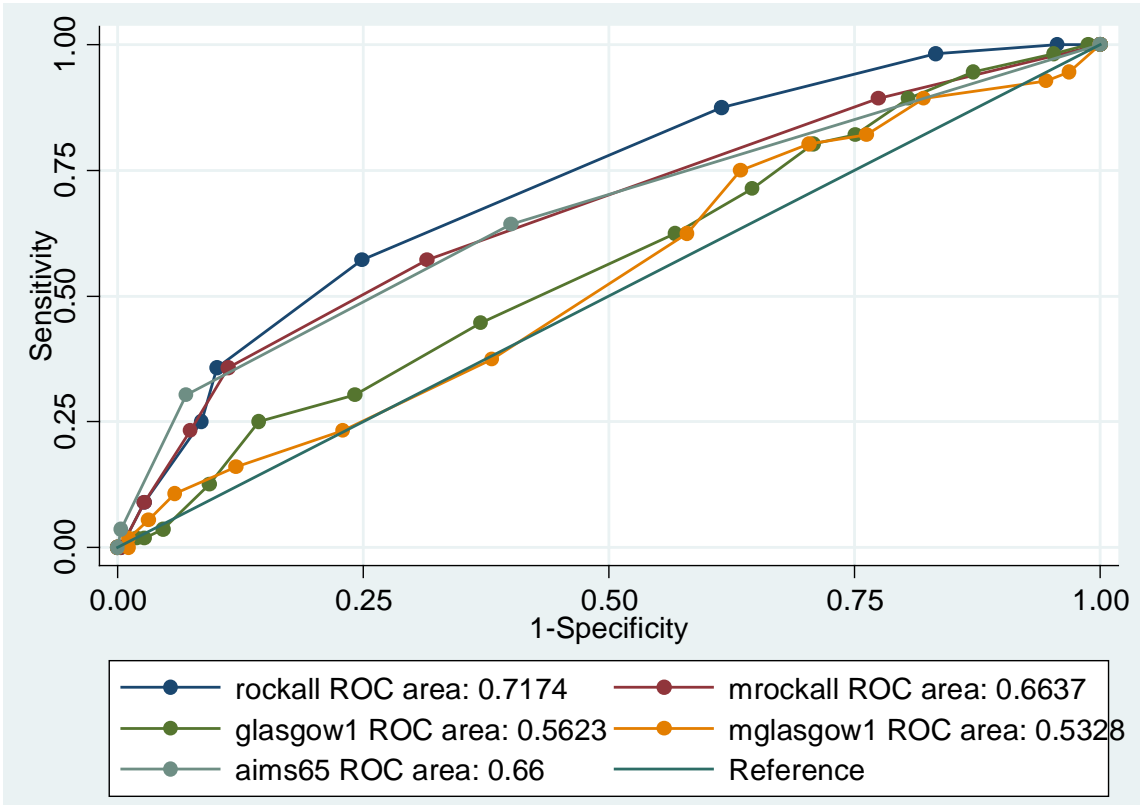

Figure 3. ROC curves in predicting the occurrence of death. ROC: Receiver Operating Characteristic. 
Table 3. Intrinsic characteristics of scores.

\begin{tabular}{ccccccc}
\hline Score & $\begin{array}{c}\text { Cut-off } \\
\text { value }\end{array}$ & $\begin{array}{c}\text { Sensibility } \\
(\%)\end{array}$ & $\begin{array}{c}\text { Specificity } \\
(\%)\end{array}$ & $\begin{array}{c}\text { PPV } \\
(\%)\end{array}$ & $\begin{array}{c}\text { NPV } \\
(\%)\end{array}$ & p \\
\hline FRS & $>2$ & 98.21 & 16.66 & 20.37 & 97.72 & 0.004 \\
CRS & $>0$ & 89.28 & 22.42 & 20 & 92.62 & 0.048 \\
GBS & $>1$ & 100 & 1.55 & 18.06 & 100 & 0.340 \\
mGBS & $>1$ & 94.64 & 3.48 & 17.54 & 75 & 0.050 \\
AIMS65 & $>0$ & 64.28 & 59.68 & 25.71 & 88.50 & 0.001 \\
\hline
\end{tabular}

PPV: Positive prediciive value; NPV: Negative predictive value; FRS: Full Rockall Score; CRS: Clinical Rockall Score; GBS: Glasgow-Blatchford Bleeding Score; mGBS: modified Glasgow-Blatchford Bleeding Score; AIMS65: Albumin, international normalized ratio, mental status, systolic blood pressure, age.

The FRS showed superior accuracy $(\mathrm{p}<0.05)$ in predicting the occurrence of rebleeding and/or death in all patients. The predictive performance of the scores was identical $(p>0.05)$ in patients hospitalised with related portal hypertension UGIB on the one hand and non-related portal hypertension UGIB on the other. However, there was significant accuracy of the mGBS in predicting death in non-related portal hypertension UGIB patients ( $\mathrm{p}<0.001$ ). The scores ("FRS" and "AIMS65") performed better in related portal hypertension UGIB patients only in predicting the occurrence of death.

The FRS and mGBS showed a superior performance in predicting the occurrence of an event in non-related portal hypertension UGIB patients; this result is comparable to those reported by several similar studies [15] [16]; the reason lies in the fact that the different scores take into account parameters that allow presumption of liver damage without quantifying this liver damage. This explains the high performance of scores that take into account a quantified assessment of liver damage in predicting the occurrence of death in related portal hypertension UGIB patients, such as the "AIMS65" [17] [18]. The AIMS65 score showed a lower performance than the FRS and CRS. This result could be explained by the low proportion of related portal hypertension UGIB in our study $(29.06 \%)$. The FRS and AIMS65 were the most accurate in predicting rebleeding, as in European series [7] [19]. As in several other studies [17], each of the scores was more accurate in predicting the occurrence of death, as opposed to rebleeding. However, Kim et al. [19] reported a high sensitivity of FRS and CRS in predicting death, and a higher sensitivity of GBS and $\mathrm{mGBS}$ in predicting rebleeding.

The FRS and CRS had shown superior accuracy (thresholds of $>2$ and $>0$ respectively) in detecting patients at low risk of rebleeding and/or death, with sensitivities of $95 \%$ and above; and $89 \%$ and above respectively. These results are in line with the literature due to the fact that the aim of developing these scores was to effectively predict the risk of rebleeding and/or death [20]. However, some studies have reported high mortality in patients below the cut-off [21] [22]. These discrepancies can be explained by epidemiological differences (age, comorbidities) between the populations studied. In line with studies reported in the literature, the FRS was more accurate than the CRS in predicting the occurrence 
of death. This is due to the fact that the FRS takes into account the fibroscopic aspects of the patients. Nevertheless, the use of the CRS is still of interest due to its efficiency (sensitivity $=89.28 \%$; negative predictive value $=90.62 \%$ ) and its purely clinical nature (making it usable in an emergency, at the patient's bed).

Considering a threshold value $>1$, the GBS and mGBS had excellent sensitivity (100\% and $96.42 \%$ respectively) in detecting low-risk patients. The GBS had a good negative predictive value (100\%). The effectiveness of these two scores in sorting patients according to risk has also been described in other series [10] [23]. However, the effectiveness of these two scores cannot be taken into account in our work ( $p>0.05)$. This lack of significance can be explained by the low number of low-risk patients in our study (1.27\% for GBS and 3.82\% for mGBS), but FRS (threshold $>2$ ) and CRS (threshold >0) showed good sensitivity (98.21\% and $89.28 \%$, respectively) and negative predictive value $(97.72 \%$ and $90.62 \%$, respectively) with $\mathrm{p}<0.05$, as in other studies [15] [24].

\section{Conclusion}

The FRS and the CRS are two accurate scores in predicting the occurrence of an incident in case of upper GI bleeding. Their high sensitivity and negative predictive value make them reliable tools for identifying high-risk patients requiring hospitalisation. However, these scores have been shown to be less accurate in cases of related portal hypertension UGIB.

\section{Conflicts of Interest}

The authors declare no conflicts of interest regarding the publication of this paper.

\section{References}

[1] Camellini, L., Merighi, A. and Pagnini, C. (2004) Comparison of Three Different Risk Scoring Systems in Non-Variceal Upper Gastrointestinal Bleeding. Digestive and Liver Disease, 36, 271-277. https://doi.org/10.1016/j.dld.2003.10.017

[2] Hearnshaw, S., Logan, R. and Lowe, D. (2007) Acute Upper Gastrointestinal Bleeding in the UK: Patient Characteristics, Diagnoses and Outcomes in the 2007 UK Audit. Gut, 60, 1327-1335. https://doi.org/10.1136/gut.2010.228437

[3] Abougergi, M., Travis, A. and Saltzman, J. (2015) The In-Hospital Mortality Rate for Upper GI Hemorrhage Has Decreased over 2 Decades in the United States: A Nationwide Analysis. Gastrointestinal Endoscopy, 81, 882-888. https://doi.org/10.1016/j.gie.2014.09.027

[4] D'amigo, G. and De Franchis, R. (2003) Upper Digestive Bleeding in Cirrhosis. Post-Therapeutic Outcome and Prognostic Indicators. Hepatology, 38, 599-612. https://doi.org/10.1053/jhep.2003.50385

[5] Chalasani, N., Kahi, C. and Francois, F. (2003) Improved Patient Survival after Acute Variceal Bleeding: A Multicenter, Cohort Study. Gastroenterology, 98, 653-659. https://doi.org/10.1111/j.1572-0241.2003.07294.x

[6] Augustin, S., Muntaner, L. and Altamirano, J. (2009) Predicting Early Mortality after Acute Variceal Hemorrhage Based on Classification and Regression Tree Analy- 
sis. Clinical Gastroenterology and Hepatology, 7, 1347-1354.

https://doi.org/10.1016/j.cgh.2009.08.011

[7] Blatchford, O., Murray, W. and Blatchford, M. (2000) A Risk Score to Predict Need for Treatment for Upper-Gastrointestinal Haemorrhage. The Lancet, 356, 1318-1321. https://doi.org/10.1016/S0140-6736(00)02816-6

[8] Saltzman, J., Tabak, Y., Hyett, B., et al. (2011) A Simple Risk Score Accurately Predicts In-Hospital Mortality, Length of Stay, and Cost in Upper GI Bleeding. Gastrointestinal Endoscopy, 74, 1215-1224. https://doi.org/10.1016/j.gie.2011.06.024

[9] Hay, J., Lyubashevsky, E., Elashoff, J., et al. (1996) Upper Gastrointestinal Hemorrhage Clinical-Guideline Determining the Optimal Hospital Length of Stay. The American Journal of Medicine, 3, 313-322. https://doi.org/10.1016/S0002-9343(97)89490-9

[10] Chen, I., Hung, M., Chiu, T., et al. (2007) Risk Scoring Systems to Predict Need for Clinical Intervention for Patients with Nonvariceal Upper Gastrointestinal Tract Bleeding. The American Journal of Emergency Medicine, 25, 774-779. https://doi.org/10.1016/j.ajem.2006.12.024

[11] Srirajanskanthan, R., Conn, R., Bulwer, C., et al. (2010) The Glasgow Blatchford Scoring System Enables Accurate Risk Stratification of Patients with Upper Gastrointestinal Haemorrhage. International Journal of Clinical Practice, 64, 868-874. https://doi.org/10.1111/j.1742-1241.2009.02267.x

[12] Bagny, A., Bouglouga, O. and Djibril, M. (2012) Profil étiologique des hémorragies digestives hautes de l'adulte au CHU-campus de Lomé (Togo). Journal Africain d Hépato-Gastroentérologie, 6, 38-42. https://doi.org/10.1007/s12157-012-0356-1

[13] Monteiro, S., Goncalves, T., Magalhaes, J., et al. (2016) Upper Gastrointestinal Bleeding Risk Scores: Who, When and Why? World Journal of Gastrointestinal Pathophysiology, 7, 86-96. https://doi.org/10.4291/wjgp.v7.i1.86

[14] Chandra, S. (2013) AIMS65 Score Predicts Short-Term Mortality But Not the Need for Intervention in Acute Upper GI Bleeding. Gastrointestinal Endoscopy, 78, 381-382. https://doi.org/10.1016/j.gie.2013.02.034

[15] Thanapirom, K., Ridtitid, W. and Rerknimitr, R. (2016) Prospective Comparison of Three Risk Scoring Systems in Non-Variceal and Variceal Upper Gastrointestinal Bleeding. Journal of Gastroenterology and Hepatology, 31, 761-767. https://doi.org/10.1111/jgh.13222

[16] Reed, E., Dalton, H. and Blatchford, O. (2014) Is the Glasgow Blatchford Score Useful in the Risk Assessment of Patients Presenting with Variceal Haemorrhage? European Journal of Gastroenterology \& Hepatology, 26, 432-437. https://doi.org/10.1097/MEG.0000000000000051

[17] Rout, G., Sharma, S., Gunjan, D., et al. (2019) Comparison of Various Prognostic Scores in Variceal and Non-Variceal Upper Gastrointestinal Bleeding: A Prospective Cohort Study. Indian Journal of Gastroenterology, 38, 158-166. https://doi.org/10.1007/s12664-018-0928-8

[18] Wang, F., Cui, S., Wang, F., et al. (2018) Different Scoring Systems to Predict 6-Week Mortality in Cirrhosis Patients with Acute Variceal Bleeding: A Retrospective Analysis of 202 Patients. Scandinavian Journal of Gastroenterology, 7, 885-890. https://doi.org/10.1080/00365521.2018.1481518

[19] Kim, B., Park, M., Kim, S., et al. (2009) Comparison of Scoring Systems for the Prediction of Outcomes in Patients with Nonvariceal Upper Gastrointestinal Bleeding: A Prospective Study. Digestive Diseases and Sciences, 54, 2523-2529. https://doi.org/10.1007/s10620-008-0654-7 
[20] Rockall, T., Logan, R., Devlin, H., et al. (1996) Risk Assessment after Acute Upper Gastrointestinal Haemorrhage. Gut, 38, 16-21. https://doi.org/10.1136/gut.38.3.316

[21] Vreeburg, E., Terwee, C. and Snel, P. (1999) Validation of the Rockall Risk Scoring System in Upper Gastrointestinal Bleeding. Gut, 44, 331-335. https://doi.org/10.1136/gut.44.3.331

[22] Atkinson, R. and Hurlstone, D. (2008) Usefulness of Prognostic Indices in Upper Gastrointestinal Bleeding. Best Practice \& Research: Clinical Gastroenterology, 22, 233-242. https://doi.org/10.1016/j.bpg.2007.11.004

[23] Badel, S., Dorta, G. and Carron, P.-N. (2011) Hémorragie digestive haute: Utilité des scores pronostiques. Revue Médicale Suisse, 7, 1574-1578.

[24] Mokhtare, M., Bozorgi, V., Agah, S., et al. (2016) Comparison of Glasgow-Blatchford Score and Full Rockall Score Systems to Predict Clinical Outcomes in Patients with Upper Gastrointestinal Bleeding. Clinical and Experimental Gastroenterology, 31, 337-343. https://doi.org/10.2147/CEG.S114860 